\title{
Flushing Out Carcinoid Syndrome: Beneficial Effect of the Anticancer Epigenetic Agent RRx-001 in a Patient with a Treatment-Refractory Neuroendocrine Tumor
}

\author{
Corey A. Carter ${ }^{a} \quad$ Aiste Degesys $^{a} \quad$ Bryan Oronsky $^{b} \quad$ Jan Scicinski ${ }^{b}$ \\ Scott Z. Caroen ${ }^{b} \quad$ Arnold L. Oronsky $^{c}$ Tony Reid $^{d} \quad$ Pedro Cabrales $^{e}$ \\ Joe Roswarski ${ }^{a}$ \\ ${ }^{a}$ Walter Reed National Military Medical Center, Bethesda, Md., bepicentRx, Inc., \\ Mountain View, Calif., 'InterWest Partners, Menlo Park, Calif., d Moores Cancer Center, and \\ ${ }^{\mathrm{e}}$ Department of Bioengineering, University of California, La Jolla, Calif., USA
}

\section{Key Words}

Epigenetics · Neuroendocrine tumor · Carcinoid syndrome

\begin{abstract}
Neuroendocrine tumors (NET) are a heterogeneous group of neoplasms defined by the presence of cells with secretory granules and the potential to produce and release high levels of vasoactive peptides into the circulation, leading to severe flushing and diarrhea, which may adversely affect quality of life. This report presents the case of a 64-year-old man with chronic refractory diarrhea due to pulmonary NET treated with the experimental anticancer agent RRx-001 in a phase II trial called TRIPLE THREAT with subsequent resolution of his diarrhea.
\end{abstract}

\section{Introduction}

As its name implies, neuroendocrine cells are nerve-like cells disseminated widely throughout the body that release neurotransmitters and hormones including gastrin, cholecystokinin, vasoactive intestinal polypeptide, substance $\mathrm{P}$ and serotonin into the circulation

\begin{tabular}{|c|c|}
\hline KARGER 125 & 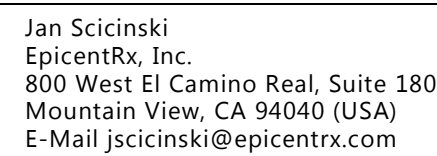 \\
\hline
\end{tabular}


Carter et al.: Beneficial Effect of RRx-001 in a Patient with a Treatment-Refractory Neuroendocrine Tumor

[1]. These cells may undergo malignant transformation to give rise to neuroendocrine neoplasms or carcinoid tumors that, not surprisingly, given the ubiquity of neuroendocrine cells in normal tissues, arise in multiple locations, including the gastrointestinal and the genitourinary tracts as well as the lungs, where they account for up to $25 \%$ of all invasive lung malignancies [2].

Neuroendocrine tumors (NET) are characterized as functional or nonfunctional, depending on whether they secrete hormones, which in turn may result in specific symptoms and signs [3]. Carcinoid syndrome refers to variable and episodic symptoms of flushing, secretory diarrhea, tachycardia or hypotension, bronchospasm, and valvular heart disease due to the overproduction and release of substances, including serotonin, histamine, prostaglandins, kallikrein, bradykinins, substance P, gastrin, corticotrophin, and neuron-specific enolase [4].

RRx-001 is an aerospace-derived, systemically nontoxic anticancer agent [5] with radio-, chemo- and immunosensitizing properties [6] under active investigation in multiple tumor types including brain, colorectal, cholangiocarcinoma and lung. In the TRIPLE THREAT clinical trial (NCT02489903), so named because patients with non-small cell lung cancer, small cell lung cancer and neuroendocrine tumors (NET) are eligible, treatment consists of weekly RRx-001 administered intravenously over about $1 \mathrm{~h}$ until RECIST v.1.1 progression followed by retreatment with formerly effective but now refractory platinum doublets. The premise is that RRx-001, as an epigenetic inhibitor of DNA methylation and deacetylation, effects changes in gene expression that will render refractory tumors sensitive to rechallenge with formerly tried chemotherapies [7]. The trial has a 3-stage design for early stopping of any of the three arms in case of lack of efficacy (fig. 1).

\section{Case Presentation}

The patient presented here is, a RET-mutation-positive (M918T), 64-year-old male with intermediate grade, extensive stage IV (T1N3M1a) pulmonary neuroendocrine carcinoma diagnosed on November 21, 2014, who participates in the TRIPLE THREAT trial. Starting on December 22, 2014, he received cisplatin/etoposide but discontinued on February 26, 2015, after 4 cycles for increasing complaints of nausea, decreased energy, and anorexia. On May 18,2015 , the patient was started on monthly 30 -mg octreotide injections to control neuroendocrine symptoms of flushing and grade 3 diarrhea, consisting of up to 12-14 watery stools per day. On long-acting octreotide, the patient reported a reduction in his bowel movements to approximately 7 per day, but they remained loose and watery. On June 24, 2015 , CT scans demonstrated progression with a new right ocular choroidal metastasis.

The patient began his first weekly infusion of RRx-001 on July 9, 2015, administered concurrently with radiation treatment to his right eye from July 14, 2015, to December 8, 2015. The octreotide was stopped when RRx-001 was started. On December 8, 2015, approximately 1 month after treatment with RRx-001 was initiated, a CT scan was performed, indicating stable disease with marked central cavitation in several tumors. A confirmatory positron emission tomography (PET)-CT scan demonstrated decreased standard uptake values, a semiquantitative measurement of the 18-F-fluorodesoxyglucose uptake on PET, in the majority of lesions (fig. 2). At the same time, since starting RRx-001, both his flushing and high-output diarrhea have significantly improved, with a reduction in the number of stools per day from 12 to 2 and increased stool consistency despite the cessation of octreotide and no use of any antidiarrheal medications (fig. 3). Urinary 5-HIAA levels have been measured prior to starting any treatment and were found not to be elevated. 
Carter et al.: Beneficial Effect of RRx-001 in a Patient with a Treatment-Refractory Neuroendocrine Tumor

\section{Discussion}

The therapeutic options for refractory carcinoid syndrome are limited. The synthetic somatostatin analogues octreotide and lanreotide, and to a lesser extent interferon-alpha, are the mainstays of treatment [8]. In the literature, vascular endothelial growth factor inhibitors such as bevacizumab, tyrosine kinase inhibitors such as sunitinib and sorafenib, which also block vascular endothelial growth factor, the antivascular agent thalidomide, and the mammalian target of rapamycin inhibitors such as everolimus have been associated with an improvement in the signs and symptoms of malignant carcinoid syndrome [3].

To our knowledge, this is the first report of a hormone syndrome control with an epigenetic agent in a functioning NET with a typical carcinoid syndrome. The mechanism by which RRx-001 may inhibit hormone release is unclear. It is possible that the epigenetic modification of gene transcription may have led to a reduction in the transcription and subsequent production of bioactive mediators such as serotonin. Alternatively, the antivascular properties of RRx-001 [9], well documented in preclinical experiments [10], may have contributed. In addition, RRx-001-induced tumor necrosis and a decrease in the number of hormone-secreting cells may have been at least partly responsible.

From this N-of- 1 study, it is manifestly impossible to draw significant conclusions about the efficacy of epigenetic agents in general, and RRx-001, in particular, in NET; however, the rapid reversal of symptoms and improved quality of life for this patient necessitates further investigation in the TRIPLE THREAT trial. These clear clinical benefits also possibly suggest that a trial of approved low-dose epigenetic agents such as 5-azacitidine or vorinostat in the context of refractory carcinoid syndrome, when all other agents have failed, may be warranted.

\section{Acknowledgment}

The study was funded by EpicentRx, Inc.

\section{Statement of Ethics}

The patient described in this case report has given his informed consent as part of the TRIPLE THREAT clinical study (NCT02489903). This study protocol has been approved by the Walter Reed National Military Medical Center Institutional Review Board.

\section{Disclosure Statement}

B.O., J.S. and S.C. are employees of and A.L.O. is an investor in EpicentRx, Inc. The remaining authors declare that they have no competing interests.

\section{References}

1 Bissette G, Manberg P, Nemeroff CB, Prange AJ Jr: Neurotensin, a biologically active peptide. Life Sci 1978;23:2173-2182.

2 Travis WD: Advances in neuroendocrine lung tumors. Ann Oncol 2010;21(suppl 7):vii65-vii71. 
Carter et al.: Beneficial Effect of RRx-001 in a Patient with a Treatment-Refractory Neuroendocrine Tumor

-3 Eads JR, Meropol NJ: A new era for the systemic therapy of neuroendocrine tumors. Oncologist 2012;17:326-338.

4 Metcalfe DD: Differential diagnosis of the patient with unexplained flushing/anaphylaxis. Allergy Asthma Proc 2000;21:21-24.

5 Reid T, Oronsky B, Scicinski J, Scribner CL, Knox SJ, Ning S, Peehl DM, Korn R, Stirn M, Carter CA, et al: Safety and activity of RRx-001 in patients with advanced cancer: a first-in-human, open-label, dose-escalation phase 1 study. Lancet Oncol 2015;16:1133-1142.

-6 Oronsky B, Carter CA, Mackie V, Scicinski J, Oronsky A, Oronsky N, Caroen S, Parker C, Lybeck M, Reid T: The war on cancer: a military perspective. Front Oncol 2014;4:387.

7 Oronsky BT, Oronsky AL, Lybeck M, Oronsky NC, Scicinski JJ, Carter C, Day RM, Rodriguez Orengo JF, Rodriguez-Torres M, Fanger GF, et al: Episensitization: defying time's arrow. Front Oncol 2015;5:134.

-8 Lamberts SW, van der Lely AJ, de Herder WW, Hofland LJ: Octreotide. N Engl J Med 1996;334:246-254.

$\checkmark 9$ Oronsky BT, Scicinski JJ, Reid T, and Knox S: Beyond antiangiogenesis: vascular modulation as an anticancer therapy - a review. Transl Oncol 2012;5:133-140.

10 Scicinski J, Oronsky B, Ning S, Minchinton A, Knox S: Abstract 4371: RRx-001 modulates intratumor blood flow in SCCVII and U87 tumors. Cancer Res 2012;72:4371.

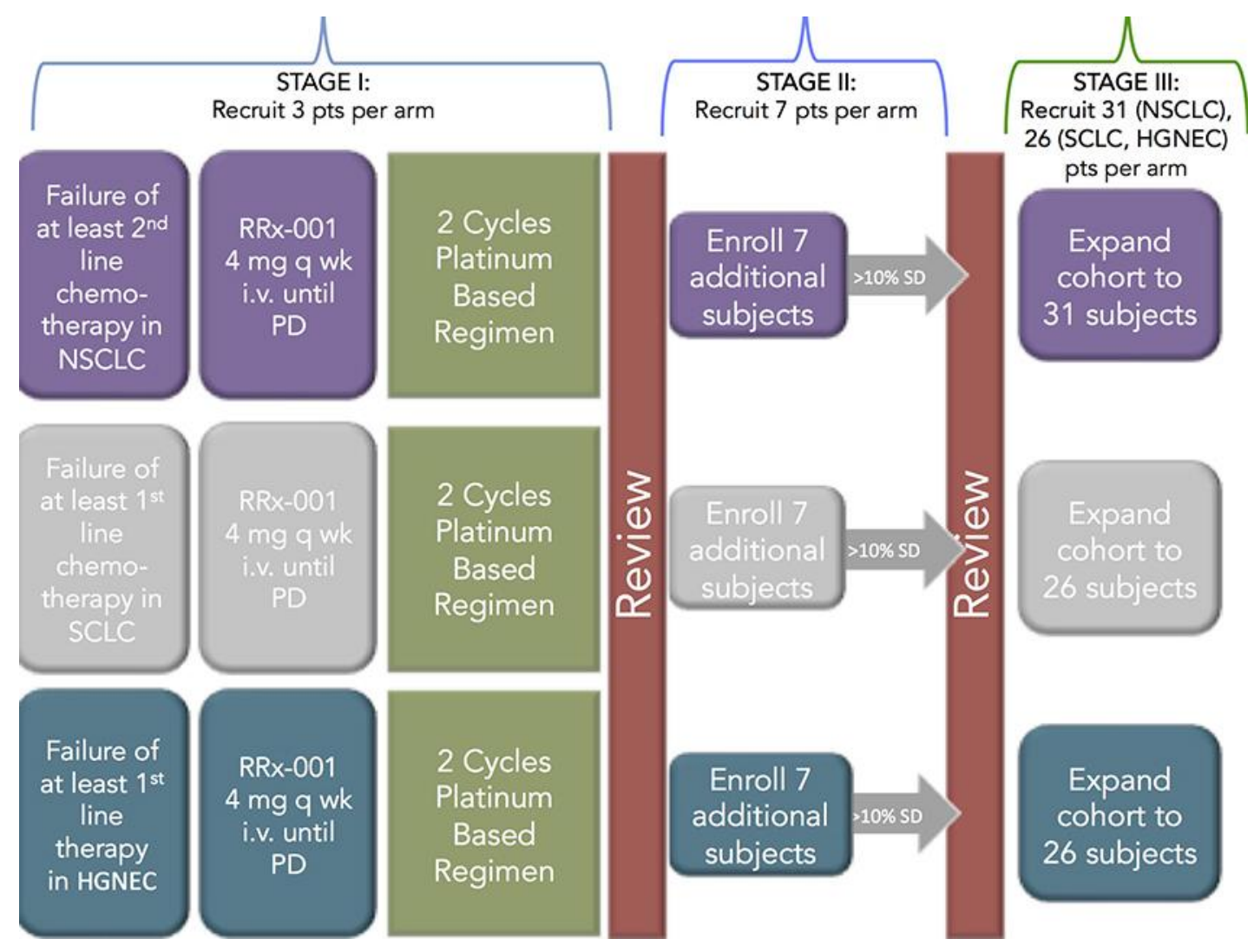

Fig. 1. Study schema for the TRIPLE THREAT study. 
Carter et al:: Beneficial Effect of RRx-001 in a Patient with a Treatment-Refractory Neuroendocrine Tumor
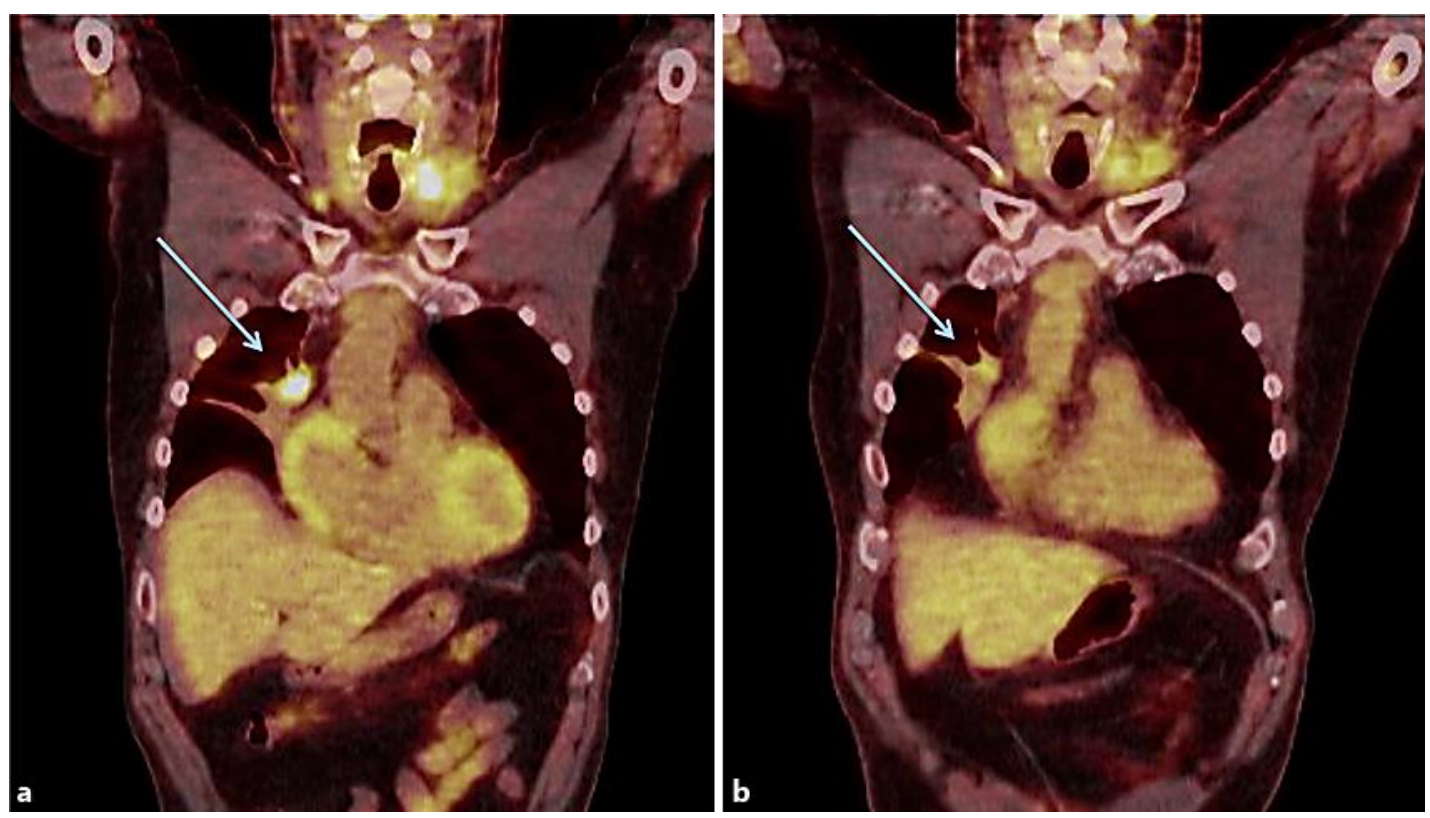

Fig. 2. a Baseline PET-CT scan showing a right anterior mediastinal metastasis. b PET-CT scan of the same region after 8 weeks of therapy with RRx-001 showing partial regression in size and decreased standard uptake values, denoting a metabolic response.

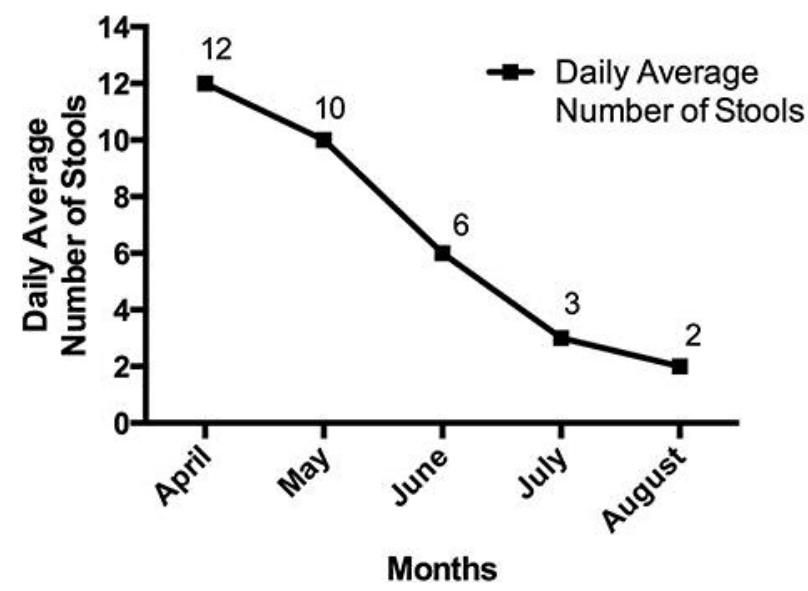

Fig. 3. Graphical presentation of the average stool number for this patient since starting RRx-001. 